\title{
O problema das elasticidades nos modelos de crescimento com restrição externa: Contribuições ao debate
}

\author{
Fabricio Jose Missio \\ Professor - Universidade Estadual de Mato Grosso do Sul - Unidade Universitária de Ponta Porã \\ Endereço: BR 463 - Km 4,5 - Ponta Porã - Mato Grosso do Sul/MS - Brasil \\ CEP: 79900-000 - E-mail: fabriciomissio@gmail.com
}

\section{Frederico G. Jayme Jr.}

Professor - Departamento de Economia (Cedeplar/UFMG)

Endereço: Av. Antônio Carlos, 6627 - Pampulha - Belo Horizonte /MG - Brasil

CEP: 31270-901 - E-mail: gonzaga@cedeplar.ufmg.br

\section{Octavio A. C. Conceição}

Professor - Univ. Federal do Rio Grande do Sul - Faculdade de Ciências Econômicas (UFRGS)

Endereço: Av. João Pessoa, 52, Campus Centro - Porto Alegre/ RS - Brasil

CEP: 90040-000 - E-mail: octavio@ufrgs.br

Recebido em 08 de fevereiro de 2013. Aceito em 04 de junho de 2014.

\section{Resumo}

O objetivo do trabalho é analisar o problema das elasticidades nos modelos de crescimento com restrição externa da tradição do crescimento puxado pela demanda agregada. Mais especificamente, analisar porque existem diferenças entre as elasticidades-renda da demanda por importações e exportações dos países industrializados em desenvolvimento com relação aos países desenvolvidos. Para tanto, inicialmente resgatamos o modelo benchmark de Thirlwall (1979), enfatizando o papel das referidas elasticidades na explicação das distintas taxas de crescimento entre os países. Em seguida, mostramos o desdobramento dos modelos demand led dessa tradição, bem como o que se considera ser uma lacuna importante dessa literatura, qual seja, a não explicação dos fatores que determinam a persistência de diferenças nas elasticidades do comércio mesmo com a industrialização de grande parte da "periferia". Por fim, são apresentadas contribuições teóricas associadas a abordagens alternativas do pensamento econômico (pós-keynesianos, evolucionários, institucionalistas) que, ao complementarem essas lacunas, avançam em questões importantes no entendimento do processo de crescimento das economias em desenvolvimento. As considerações finais mostram que as elasticidades-renda do comércio exterior dependem de uma série de características estruturais da economia (devem ser consideradas como endógenas nos referidos modelos) e que a persistência de diferenças requer uma análise mais complexa do processo de crescimento.

\section{Palavras-Chave}

Crescimento econômico. Restrição externa. Evolucionismo. Institucionalismo.

- Gostaríamos de agradecer os comentários de parecerista anônimo. Os autores agradecem o apoio do Cnpq e à Fapemig (Programa Pesquisador Mineiro). Os erros remanescentes são de nossa inteira responsabilidade. 


\section{Keywords}

Growth. Balance of payments. Evolutionism. Institutionalism.

JEL Classification

O41, E12, B52.

\section{Introdução}

A tradição do crescimento puxado pela demanda agregada leva em consideração a existência de restrições advindas da estrutura produtiva que impedem a expansão sustentável da demanda de forma compatível com o equilíbrio intertemporal da conta corrente (restrição externa) do Balanço de Pagamentos (BP). Essa tradição tem suas origens no modelo kaldoriano (Kaldor, 1966), segundo o qual o processo de contínua migração de mão de obra do setor atrasado ${ }^{1}$ para o setor industrial é responsável pela formação do "mercado interno" de um país e, conjuntamente com o investimento, constitui o principal componente da demanda nos estágios intermediários de desenvolvimento. Quando um país esgota as possibilidades de expansão da demanda via aumento do seu mercado interno, as exportações tornam-se o principal componente de expansão da demanda e, consequentemente, o desempenho de um país no comércio internacional é fundamental para sustentar taxas de crescimento elevadas.

A ênfase de Kaldor na evolução das exportações como o principal componente da demanda final levou autores como Dixon e Thirlwall (1975), Thirlwall (1979), McCombie e Thirlwall (1994), entre outros, a formalizar suas ideias com base no "multiplicador do comércio internacional de Harrod", cuja demonstração conduz à conclusão de que a taxa de crescimento da economia é determinada pela taxa de crescimento das exportações e pela elasticidade-renda da demanda por importações (modelos de crescimento com restrição de equilíbrio do BP). ${ }^{2}$

O benchmark dessa tradição é o modelo de Thirlwall (1979), segundo o qual o crescimento econômico de longo prazo pode ser explicado pelas condições de demanda, que determina uma restrição

1 O Setor atrasado em geral é o setor agrícola com baixa produtividade.

2 Admite-se que o modelo export led é mais amplo dos que os modelos de crescimento com restrição externa, entendido esses como um desdobramento particular do primeiro. 
externa ao crescimento, na qual as elasticidades-renda da demanda por importação e exportação exercem papel fundamental. A questão é que as explicações sobre os determinantes dessas elasticidades dentro dessa abordagem são insuficientes, ainda que seja consensual que elas reflitam em grande parte a diversidade e o grau de sofistificação da estrutura produtiva de uma economia. Recentemente, como forma de contornar essa questão, alguns autores têm incluído em suas análises a hipótese de endogeneidade das elasticidades-renda do comércio internacional. O objetivo deste artigo é o de apresentar algumas das contribuições que complementam e avançam na fundamentação dessa hipótese advinda das abordagens pós-keynesiana, evolucionária e institucionalista, sobretudo no que se refere ao entendimento de como ocorre o progresso tecnológico.

A diferença a ser ressaltada é que, ao invés das referidas elasticidades serem consideradas apenas como funções de variáveis macroeconômicas - como do excesso de capacidade (Palley, 2002) ou a dependência em relação às taxas de crescimento passadas (McCombie e Roberts, 2002) ou, ainda, como funções da participação das manufaturas no produto doméstico (Botta, 2009) ou da taxa real de câmbio (Ferrari, Freitas e Barbosa-Filho, 2013; Missio e Jayme Jr., 2012) - elas devem também ser consideradas como endógenas a um novo conjunto de variáveis. Essas variáveis são representadas pelo Sistema Nacional de Inovações de um país e pelo conjunto de suas Instituições, com importantes implicações em termos de política econômica.

É possível, com isto, demonstrar que a diversidade e o grau de sofisticação da estrutura produtiva, elementos assumidos como determinantes das elasticidades-renda nos modelos originais (embora não explicitado), são endógenos a esse novo conjunto de variáveis. Com efeito, a incorporação desses argumentos permite estabelecer um raciocínio lógico sequencial que, ao complementar a referida tradição, contribui para melhorar a fundamentação teórica sobre os determinantes do processo de crescimento dos países em desenvolvimento. Especificamente, essas conexões permitem avançar na construção de um núcleo teórico comum capaz de explicar quais os determinantes fundamentais das elasticidades-renda do comércio internacional (hipótese de endogeneidade das elasticidades). 
O trabalho encontra-se dividido em quatro seções, além desta introdução e das considerações finais. A segunda seção apresenta o modelo de Thirlwall (1979) como representativo da tradição keynesiana-estruturalista; a seção seguinte, o desdobramento dos modelos pós-keynesianos dessa tradição. A quarta seção apresenta as contribuições ao entendimento do problema das elasticidades advindo da abordagem evolucionária, enquanto a seção 5 faz uma apreciação das contribuições do pensamento institucionalista.

\section{O modelo benchmark de Thirlwall (1979)}

Esse modelo mostra uma simples relação que indica a taxa de crescimento que uma nação pode alcançar sem sofrer deterioração no seu Balanço de Pagamentos (BP). Essa relação pode ser sintetizada na denominada Lei de Thirlwall:

$$
y=\varepsilon . z / \pi=x / \pi
$$

em que $y$ é a taxa de crescimento da renda doméstica; $\varepsilon$ é a elasticidade-renda das exportações $(\varepsilon>0) ; z$ é a taxa de crescimento da renda externa; $\pi$ é a elasticidade-renda das importações $(\pi>0)$ e $x$ é a taxa de crescimento das exportações. A Equação 1 mostra que a taxa de crescimento compatível com o equilíbrio do BP é igual a razão entre a taxa de crescimento das exportações e a elasticidade-renda da demanda por importações.

O modelo de Thirlwall (1979) pode ser usado para responder à questão central da teoria sobre o motivo de as taxas de crescimento diferirem entre os países (Cimoli et al., 2010). A relação entre restrição do BP e convergência do crescimento é representada na Figura (1). Quatro cenários podem ser identificados:

1. Convergência sustentável - ocorre quando a taxa de crescimento efetiva dos países em desenvolvimento é maior do que a unidade e ao mesmo tempo é menor ou igual à razão das elasticidades $(\varepsilon / \pi)$ (Figura 1, quadrante nordeste $\mathrm{A}$, em que $\varepsilon / \pi \geq y / z>1)$

2. Divergência sustentável - ocorre quando os países em desenvolvimento crescem menos do que o resto do mundo en- 
quanto mantêm o equilíbrio (ou superávit) em conta corrente (Figura 3, quadrante sudeste $\mathrm{D}$, em que $\varepsilon / \pi \geq y / z<1$ ). Nesse caso, o país cresce menos do que o permitido pela restrição de equilíbrio do BP;

3. Convergência insustentável - ocorre quando a taxa relativa de crescimento (razão das elasticidades) é maior (menor) que a unidade (Figura 1 , quadrante noroeste $B$, em que $\varepsilon / \pi<y / z>1)$. A convergência, nesse caso, ocorre com o aumento da dívida externa. Todavia, em algum ponto do tempo esse débito pode se tornar insustentável, de tal forma que o processo de convergência será interrompido.

4. Divergência insustentável - ocorre quando a razão das elasticidades é menor que a taxa de crescimento efetiva, o que implica déficits crescentes em conta corrente (Figura 1, quadrante sudoeste $C$, em que $\varepsilon / \pi<y / z<1$ ). Nesse caso, a taxa de crescimento prevalecente no país é insuficiente para produzir convergência com a economia internacional.

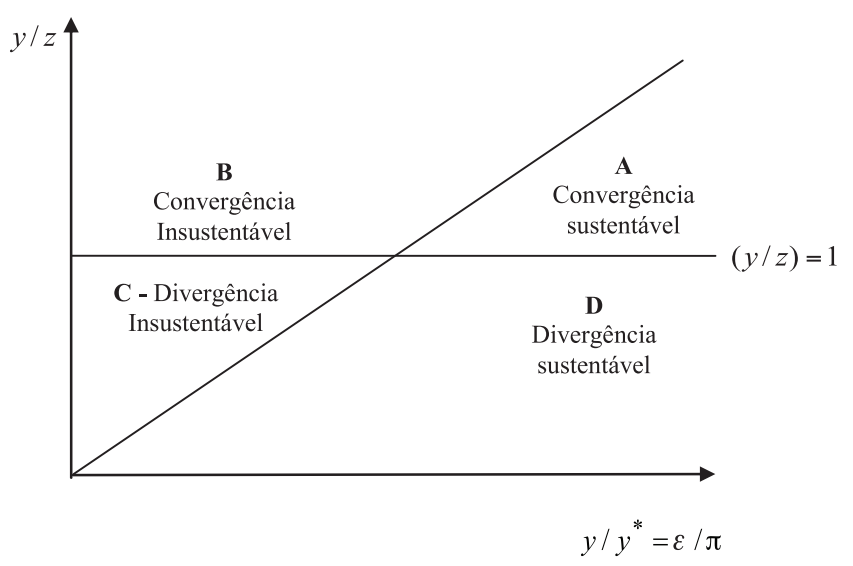

Figura 1: Convergência, divergência e restrição externa

Fonte: Cimoli et al. (2010).

Um dos principais desdobramentos dessa abordagem é a lei multissetorial de Thirlwall (Araújo e Lima, 2007). Os autores derivam uma taxa de crescimento com equilíbrio no $\mathrm{BP}$, análoga à lei de Thirlwall, com uma estrutura macrodinâmica multissetorial pasinettiana. O resultado mostra que a taxa de crescimento da renda per capita de um 
país se relaciona às elasticidades-renda setoriais das exportações e importações de um país. Essas elasticidades são ponderadas pelos coeficientes que medem a participação de cada setor no total das importações e exportações, respectivamente.

A principal implicação do modelo multissetorial é que alterações na composição da demanda, que não se refletem em mudanças nas elasticidades, mas na participação de cada setor na exportação ou importação agregada, também importam para o crescimento econômico. Ou seja, o crescimento com equilíbrio no BP depende das elasticidades-renda do comércio exterior e da composição setorial da economia.

Em síntese, existe um "problema das elasticidades", ou seja, o crescimento dos países é restrito pela condição de equilíbrio no BP e esta restrição encontra na composição setorial e na magnitude das elasticidades-renda da demanda do comércio exterior elementos essenciais para seu entendimento. O ponto é que as explicações referentes aos fatores que determinam a persistência de diferenças nas elasticidades do comércio exterior, mesmo com a industrialização de grande parte da "periferia", não são satisfatórias. Como veremos a seguir, essas explicações podem encontrar um maior respaldo ao incorporar argumentos de diferentes abordagens econômicas.

\section{A contribuição pós-keynesiana}

Do ponto de vista teórico, existe uma série de contribuições pós-keynesianas que ampliam as conclusões do modelo benchmark ao analisar, por exemplo, o papel do fluxo de capitais (Thirlwall e Hussain, 1982), o endividamento externo (Elliot e Rhodd, 1999) e o serviço de juros da dívida externa (Moreno-Brid, 2003), entre outros. Concomitantemente, trabalhos empíricos tendem a não rejeitar, para economias em desenvolvimento, a hipótese de validade da restrição externa.

A principal conclusão desses modelos é que diferenças nas elasticidades entre os países têm como consequência distintos graus de restrição ao crescimento econômico. A questão fundamental torna- 
se, portanto, entender os determinantes dessas elasticidades. Como observado por Prebisch (2000b), a divisão internacional entre economias agrárias (periféricas) e industriais (centrais) determina que as primeiras, ao produzirem essencialmente bens primários de baixo conteúdo tecnológico (baixa elasticidade-renda da demanda por exportações) e demandarem bens industrializados com alto conteúdo tecnológico produzidos das economias centrais (bens com alta elasticidade-renda da demanda por importações), tenham uma reduzida taxa de crescimento compatível com o equilíbrio no BP.

Com efeito, as diferenças nos determinantes no grau de atração pelos produtos não são explicitados. Em outras palavras, não há uma explicação consistente do motivo de a demanda (o grau de atração) dos produtos produzidos nos países em desenvolvimento ser menor do que aqueles produzidos nos países desenvolvidos. Uma explicação alternativa é dada por Fajnzylber $(1983,2000)$, cuja argumentação é que o elevado grau de restrição externa de uma economia agrária não seria superado por meio da sua industrialização se ela fosse desprovida de "um núcleo endógeno de dinamização do progresso tecnológico", ou seja, inovações tecnológicas endógenas, presentes principalmente na indústria de bens de capital, são a chave para os ganhos de competitividade (Resende e Torres, 2008). No entanto, este ponto não foi explorado.

Existe, portanto, uma lacuna teórica no que se refere à explicação da persistência de diferenças nessas elasticidades mesmo com a industrialização de grande parte da "periferia". Essas diferenças de elasticidades entre países industrializados não são totalmente contempladas na explicação original, tendo em vista que ela se referia a países "agrários" e "industriais", tampouco na interpretação de que esse "um núcleo endógeno" seria capaz de afetá-las. O que se deduz dessas "primeiras explicações" é que o maior desenvolvimento tecnológico, ao afetar as elasticidades-renda do comércio, implicaria um afrouxamento da restrição externa ao crescimento.

Para avançar no entendimento de como o progresso técnico afeta as elasticidades e, mais precisamente, quais são os seus condicionantes, é necessário compreender, em primeiro lugar, que o referido progresso está vinculado ao desenvolvimento de uma estratégia delineada pelo próprio conceito de "núcleo endógeno de dinamização tecnológica". Este consiste em uma matriz industrial e produtiva 
que envolve uma infraestrutura científico-tecnológica estreitamente inserida e vinculada ao aparato produtivo, na qual a criatividade e o aprendizado se retroalimentam em e entre certas atividades e ramos essenciais. Essa retroalimentação favorece e origina o desenvolvimento tecnológico no conjunto do aparelho produtivo, ao qual vai se incorporando por meio de sucessivas inovações através do investimento que, por sua vez, sustenta a acumulação de capital e o próprio crescimento da produção, globalmente considerada (Rodriguez, 2009). Observa-se, portanto, que esse movimento de tripla face (continuidade dinâmica da acumulação, crescimento e a consequente incorporação contínua do progresso técnico) determina a competitividade genuína, definida como sendo aquela proveniente do aumento da produtividade e da incorporação de progresso técnico.

O desenvolvimento do "núcleo endógeno" reforça, assim, a inserção internacional especializada, pois articula a produção em torno de setores com maior conteúdo tecnológico que, junto com a ampliação do mercado interno, garante a realização (vendas) da produção. A articulação desses setores é importante por exercer uma influência positiva sobre o aprendizado e o progresso técnico em atividades inscritas em outros ramos industriais e em outros setores produtivos, difundindo uma "lógica industrial" para o conjunto da sociedade, aumentando a produtividade e, portanto, para o virtual incremento da competitividade nos mercados internos e internacionais, o que melhora a inserção externa e relaxa as restrições advindas da condição de crescimento com equilíbrio do BP.

Em segundo, concomitante ao desenvolvimento do "núcleo endógeno", reconhece-se que grande parte dessa explicação (para a diferença entre as elasticidades) passa pela presença de divergências estruturais, sobretudo em relação à evolução, a trajetória e a forma como o progresso técnico se propaga em cada economia e entre os países. A presença destas divergências estruturais encontra respaldo na teoria evolucionária, em especial na análise do papel desempenhado pelo Sistema Nacional de Inovações.

Neste contexto, a incorporação multissetorial do modelo de Thirlwall, não somente guarda estreita relação com a teoria evolucionária, mas também é parte de esforço de conexão teórica entre as duas tradições, na medida em que relaciona diretamente o efeito demanda e suas relações com o aumento da produtividade, via Lei 
de Verdoorn, bem como o papel da inovação tecnológica. Com efeito, a formalização da competição schumpeteriana e seu papel central no crescimento econômico, no "survey" apresentado em Silverberg and Verspagen (2006) deixa claro este ponto. Llerena and Lorentz (2004a, 2004b) contribuem na direção de articular a visão schumpeteriana de tecnologia com o efeito demanda via Lei de Verdoorn. Finalmente, León-Ledesma (2000) também avança ao modelar o processo de causação circular cumulativa dentro da tradição pós keynesiana. Aqui pretendemos avançar ainda mais sobre este tema ao conectar o "problema das elasticidades", que é o corolário da integração evolucionária com a pós keynesiana, com as contribuições institucionalistas. ${ }^{3}$

\section{Contribuições evolucionárias: o papel do catching up e do Sistema Nacional de Inovações (SI)}

Existe uma série de razões que sugerem uma potencial interação teórica e metodológica entre as correntes pós-keynesiana e evolucionária, particularmente porque ambas as abordagens entendem que o processo de desenvolvimento é multicausal, que a história e as instituições importam e que a tecnologia exerce papel central para o desenvolvimento. Além disso, admitem que concentração de renda e o limite do mercado interno têm efeitos sobre os processos econômicos, assim como a elevada concentração dos recursos financeiros e tecnológicos nos países centrais tem implicações sobre a concentração internacional da renda (divergência).

Ressalta-se, ainda, que a estrutura de demanda também é um ponto de conexão importante entre a tradição do crescimento puxado pela demanda agregada e a abordagem evolucionária, uma vez que, para a primeira, a distribuição desigual da renda - que condiciona os padrões de demanda - afeta a orientação do progresso tecnológico, enquanto para a segunda é um dos principais determinantes chave para este progresso. ${ }^{4}$ Isso implica, segundo Albuquerque (2007), que

3 O'Hara (2007) apresenta uma importante contribuição na integração da literatura heterodoxa sobre este tema, avançando, inclusive, na introdução de aspectos institucionalistas. Seu ponto, no entanto, é o de introduzir a discussão da política econômica.

4 Segundo Dosi (1988) e Klevorick et al. (1995), os determinantes do progresso tecnológico são as oportunidades de inovação para cada paradigma, as condições de apropriabilidade da inovação, a cumulatividade e os padrões de demanda que as empresas enfrentam. Mowery 
na periferia a formação dos SI deve estar acompanhada de uma construção institucional que melhore a distribuição de renda. Em outras palavras, é necessário atuar sobre a heterogeneidade das dimensões científicas, tecnológicas e sociais como forma de superação do "atraso institucional".

Essas similaridades sugerem que ambas as abordagens devem se beneficiar deste diálogo. Seguindo este raciocínio e os objetivos deste trabalho, admite-se que as explicações que buscam justificar os determinantes para os diferencias de elasticidade devem incorporar a teoria evolucionária e o seu entendimento quanto às forças e processos multifatores que estão por trás da construção institucional que molda o SI e, por conseguinte, dos mecanismos necessários para a realização do catching $u p$.

A "hipótese de catching up" (Abramovitz, 1986), cuja origem teórica remonta aos argumentos de Schumpeter (1934, 1943), dividem os países em dois grupos: o primeiro grupo é constituído por "países líderes", responsáveis pelos deslocamentos na fronteira de conhecimento científico, portanto responsáveis pelas principais inovações tecnológicas mundiais. O segundo é formado pelos países "seguidores", que não possuem infraestrutura científica para deslocar a fronteira de conhecimento, mas que podem alavancar seu progresso tecnológico a partir de duas fontes. Uma delas, que está centrada na difusão internacional de tecnologia, é absorver as inovações desenvolvidas nos países líderes pela imitação tecnológica, e a segunda é desenvolvê-las a partir dos avanços científicos realizados pelos países líderes, o que caracterizaria "janelas de oportunidade".

A questão fundamental para os países seguidores é que ambas as possibilidades de progresso tecnológico envolvem custos relativos menores do que para o grupo de países líderes (Perez \& Soete, 1988). Se os primeiros conseguirem absorver de maneira eficiente as novas tecnologias, existe a possibilidade de que possam sustentar uma taxa de crescimento da produtividade do trabalho (proxy para o progresso

e Rosenberg (1979) admitem que a existência de demanda para um eventual produto é essencial, mas reconhecem que a operação de um complexo e diverso conjunto de mecanismos de oferta está continuamente alterando a estrutura dos custos de produção e, portanto, são também fundamentais para explicar o "timing" do processo de inovação. Vale lembrar, segundo Albuquerque (1997), que, desde Adam Smith, a teoria econômica indica a relação entre a dimensão do mercado e a divisão do trabalho. Ainda segundo o autor, as condições de demanda têm importantes contribuições sobre a cumulatividade e o aprendizado tecnológico. Sobre este ponto, ver também O'Hara (2007). 
tecnológico) acima das taxas alcançadas pelo segundo grupo. A essência da hipótese de catching up é que, quanto maior o hiato tecnológico entre líderes e seguidores, maior é o potencial de progresso tecnológico desses últimos, desde que eles tenham "capacitação social" necessária para participar do processo de difusão internacional de tecnologias (Abramovitz, 1986). Ao absorverem tecnologias estrangeiras de maneira eficiente, a taxa de alcance tecnológico dos países atrasados será tanto maior quanto mais distantes estiverem dos avançados. Dessa forma, o "processo de catching up" ocorre quando um país seguidor consegue sustentar ao longo do tempo um progresso tecnológico superior ao dos líderes em função de uma significativa eficiência na absorção tecnológica. No entanto, o atraso tecnológico não é condição suficiente para que ocorra este processo. É necessário que o país atrasado apresente uma série de características socioeconômicas que lhe permitam obter as "vantagens do atraso". (Freeman, 1995; Nelson, 1993; Albuquerque, 1999; Fagerberg, 1994).

Missio e Jayme Jr. (2013) ressaltam, em primeiro lugar, o caráter tácito e local da tecnologia que está implícito nesse conceito de SI. Mais especificamente, a ideia de que ele deve ser construído e de que não pode ser simplesmente importado. Isso significa que o processo de globalização, por um lado, não garante homogeneização ao progresso técnico e, por outro, que o caráter local e institucional da tecnologia pressupõe que cada economia seja capaz de desenvolver o seu SI, de forma a criar as precondições para a realização das atividades inovativas.

Em segundo lugar, destacam a não linearidade e a instabilidade das mudanças tecnológicas como fontes da variedade e complexidade da dinâmica econômica, não sendo fenômenos transitórios e perturbadores. A mudança econômica é um processo irreversível em que o tempo e a dinâmica complexa desempenham um papel fundamental. Sendo assim, o conceito de SI pode ser entendido como uma construção institucional que impulsiona o progresso técnico em economias capitalistas complexas, seja produto de uma ação planejada e consciente, seja de um somatório de decisões não planejadas e desarticuladas (Freeman, 1988; Nelson, 1993).

Por fim, observam que, diante deste arranjo institucional, o fluxo de informações, imprescindível para a inovação tecnológica, passa a ser amplamente difundido. Segundo Dosi (1988, p. 1130), 
"Certainly, a good part of "science" can be embodied in "information". Nesse sentido, a dinâmica da inovação, base do processo de transformação econômica, depende, não só dos recursos destinados para este fim, mas, sobretudo, do processo de aprendizagem (que é cumulativo, sistêmico e idiossincrático) e da difusão tecnológica. A base de aprendizagem está no conhecimento universal ou específico, articulado ou tácito e público ou privado (Dosi, 1988). Esses aspectos são importantes porque permitem melhorar o entendimento microeconômico do progresso técnico, bem como os mecanismos de retroalimentação entre a micro e a macroeconomia. Logo, a microeconomia evolucionária é um complemento natural aos modelos macroeconômicos pós-keynesianos de crescimento com restrição externa. Em síntese, essa complementação advém da compreensão dos seguintes elementos (Cimoli e Porcile, 2011b, p. 15-16):

a) O aprendizado é local e as firmas aprendem com as competências e capacidades tecnológicas existentes;

b) O aprendizado possui um forte componente tácito, de forma que em muitos casos a tecnologia não pode ser copiada ou transferida de forma codificada (com manuais ou instruções), ou seja, a experiência na produção é essencial;

c) O progresso técnico mostra fortes elementos de dependência de trajetória (path dependence), o que implica que o passado se projeta na evolução futura das capacidades;

d) Os processos de inovação e de difusão são fortemente ligados, já que não há difusão sem o esforço das firmas imitadoras por adaptar ou melhorar a tecnologia estrangeira à luz das condições específicas de suas mercadorias e capacidades. Embora cada uma delas tenha um impacto individual pequeno, ao longo do tempo, geram aumentos significativos de produtividade e competitividade internacional;

e) Existem elementos de retornos crescentes, muitos deles marcados pela aprendizagem, que explicam fenômenos de acumulação de capacidades por um lado, e de atrasos crescentes, por outro. As firmas que mais inovam em um período são as que possuem maior probabilidade de inovar no período seguinte. Os retornos crescentes se associam a dis- 
tintos tipos de complementariedade entre ativos produtivos e tecnológicos, e as várias formas de sinergia a nível meso e macroeconômico. Essas sinergias podem gerar ciclos virtuosos de aprendizagem, inversão e crescimento;

f) O progresso técnico emerge de um processo de interação, de tentativa e erro e do intercâmbio de informações de que participa um conjunto amplo e heterogêneo de agentes, muitas vezes com objetivos diferentes, regras e estruturas organizacionais muito diversas (por exemplo, firmas, universidades e centros de investigação). A existência de um marco institucional adequado, formal e informal, que coordene a interação desses agentes e induza comportamentos cooperativos a favor da inovação e da difusão, é a chave para determinar a difusão do progresso técnico;

g) Não há trajetória predeterminada para o progresso técnico. Seu próprio caráter tácito, idiossincrático e específico para certa realidade, faz com que distintas trajetórias e bifurcações sejam possíveis. Além disso, o desenho institucional e a política industrial, tecnológica e educacional podem afetar fortemente seu rumo, de tal forma que há espaços para que a sociedade tome decisões estratégicas acerca de quais são os caminhos desejáveis;

h) Cada caminho tecnológico implica certa trajetória de mudança estrutural, de evolução do emprego e da distribuição de renda. Alguns caminhos são mais favoráveis à redução da heterogeneidade, e o caminho a ser seguido não é predeterminado nem inevitável, mas sim fruto de decisões que refletem as instituições e as políticas adotadas.

É possível, pois, argumentar que, quanto mais desenvolvido é o SI de um país, maior o progresso tecnológico e mais elevados são os ganhos de competitividade desta economia. Assim, países que possuem um SI imaturo, que são em sua grande maioria países em desenvolvimento, vão incorrer em recorrentes desequilíbrios no BP advindos, sobretudo, da baixa competitividade dos seus produtos no mercado internacional. Essa baixa competitividade, que se traduz na menor elasticidade-renda da demanda por exportações do que a elasticidade-renda da demanda por importações, está relacionada com questões estruturais ligadas ao arcabouço institucional e, portanto, ao conteúdo tecnológico incorporado aos produtos domésticos destina- 
dos ao mercado interno e externo. Ou seja, como o SI nesses países é imaturo, o progresso tecnológico fica comprometido e a atividade inovativa gera déficits em conta corrente que ativam a restrição externa ao crescimento (Missio e Jayme Jr., 2013). A chave para o rompimento dessa restrição ao crescimento econômico está na mudança no padrão de especialização das exportações em direção a produtos intensivos em tecnologia, ou pelo menos garantir um progresso tecnológico endógeno capaz de aumentar a flexibilidade produtiva desses países, evitando a especialização produtiva em commodities primárias, menos por opção e mais por falta de alternativas. ${ }^{5}$

Estabelece-se, assim, a conexão entre a teoria evolucionária e a literatura dos modelos de crescimento com restrição externa. Nesse caso, uma das principais contribuições evolucionárias decorre das explicações sobre as mudanças estruturais endógenas que determinam as diferenças de elasticidades-renda do comércio. Ou seja, admite-se que as elasticidades sejam endógenas ao desenvolvimento do SI e, por conseguinte, ao progresso tecnológico, hipótese não contemplada originalmente. Não obstante, é necessário avançar no entendimento de como ocorre o progresso tecnológico, o que evidentemente passa pela análise institucionalista. E este avanço se dá de forma distinta daquele apresentado por Llerena and Lorentz (2004b).

Em outras palavras, cumpre ressaltar que interpretações sobre as condições socioeconômicas e/ou sobre o papel das instituições anteriormente referidas - parte importante da explicação sobre a presença de diferenças estruturais entre as economias e, consequentemente, da diferença nas elasticidades-renda do comércio - são complementadas pela abordagem institucionalista. Isso implica, como veremos a seguir, que o próprio entendimento de como ocorre o processo de crescimento econômico ganha complexidade, uma vez que o mesmo pode ser resultante da adoção de distintas trajetórias nacionais, de interações não voluntárias e/ou de diferentes formas de interação da lógica nacional de mercado de um país com seus principais parceiros comerciais, entre outros.

5 E este é um ponto importante. Exportar commodities primárias, em si, não é problema. Austrália e Noruega exportam. O padrão de especialização do comércio exterior é problemático quando acompanhado de falta de alternativas.

Estud. Econ., São Paulo, vol.45, n.2, p.317-346, abr.jun. 2015 


\section{Contribuições institucionalistas}

Para a tradição institucionalista, o processo de crescimento econômico resulta da interação entre a mudança institucional e tecnológica, o papel das firmas e as instituições. Tal perspectiva analítica se faz presente também nas abordagens evolucionárias, de inspiração neo -schumpeteriana, como se viu no item anterior. A comunhão entre essas duas abordagens se estabelece a partir de dois aspectos: a) o desenvolvimento econômico é um processo multifacetado, desordenado e incerto, que exige a investigação das condições que permitem seu avanço de maneira historicamente diferenciada; e b) a mudança tecnológica, as características das firmas e as instituições, em conjunto, moldam padrões específicos de desenvolvimento. Vários autores, de ambos os matizes comungam nesse sentido, razão pela qual faremos uma rápida apreciação das contribuições de Douglass North, Matthews, Zysman e Nelson.

O conceito de instituição como conjunto de normas, regras, hábitos e sua evolução (Hodgson, 1998; North, 1990; e Nelson, 1995) vem assumindo uma significativa, inovadora e desafiadora dimensão analítica, quando inserido em diferentes contextos. A partir daí constata-se que a própria noção de instituição, em função das raízes históricas e estruturais que lhe são específicas, passa a viabilizar distintas trajetórias de crescimento em seus respectivos ambientes socioeconômicos. Por esta razão, instituição e crescimento econômico são conceitos umbilicalmente vinculados. Entretanto, qual a relação entre ambos?

\subsection{O crescimento nos institucionalistas}

Algumas considerações são decisivas para incorporar teoricamente a noção de crescimento econômico nos institucionalistas. Em que pese o grande número de estudos recentes que explicitam os elementos centrais de uma análise institucionalista, pode-se, genericamente, agrupá-las em três approaches: o Antigo Institucionalismo NorteAmericano de Veblen, Commons e Mitchell; a Nova Economia Institucional (NEI) de Coase, Williamson e North; e o NeoInstitucionalismo de Hodgson, Samuels e Rutherford (Samuels, 1995, Hodgson, 1993). Há nessas três abordagens alguns pontos consensuais no que tange ao papel das instituições no referido processo, 
mas também grandes divergências, principalmente na comparação dos Antigos e Neo-institucionalistas com os economistas da NEI.

A semelhança entre essas três correntes se dá, em primeiro lugar, pelo entendimento de crescimento econômico como "processo", o que implica incorporar seu ambiente histórico e suas especificidades locais. Em segundo lugar, por conta destas especificidades, não se poderia pressupor que trajetórias individuais apresentadas por determinadas economias possam ser historicamente copiadas, revelando que o desdobramento institucional para o crescimento econômico é necessariamente marcado pela "incerteza" e pela especificidade histórica. Em terceiro lugar, o processo de crescimento econômico, em que pese o amplo espectro de instituições - entendidas como um conjunto de normas, regras e hábitos e sua evolução (North, 1994, Hodgson, 1993) -, tem uma referência na ação individual dos agentes, que revela necessária e fundamentalmente a importância das firmas, organizações, e, portanto, do ambiente microeconômico na definição das diferentes trajetórias.

\subsection{Crescimento econômico vs. otimalidade, equilíbrio e eficiência}

Um ponto que afasta os institucionalistas da abordagem neoclássica de crescimento (e dos modelos de crescimento endógeno) é a tendência em seguir os parâmetros de convergência ou otimalidade em relação a trajetórias de crescimento. Ao contrário, nada assegura que a ação dos indivíduos em seus movimentos garanta comportamento ótimo. Em outras palavras, para os seguidores do Antigo Institucionalismo de Veblen - como Hodgson, por exemplo - há forte discordância em que os rígidos pressupostos da racionalidade (substantiva) da teoria econômica sejam capazes de proporcionar explicações factíveis e realísticas, no sentido de que o comportamento humano seja capaz de ser considerado "eficaz", em contextos onde já exista uma considerável experiência comum. Entretanto, para os teóricos filiados à NEI, as instituições definem, modelam e mantêm o referido "comportamento racional" nos diferentes contextos: os indivíduos não deduzem ou pensam por si mesmos sobre o que é uma ação adequada, senão que atuam apenas fazendo o que é convencional no respectivo contexto (Nelson; Sampat, 2001). Ainda que Commons aceite que os costumes, as normas e as regras possam 
surgir espontaneamente, assinala o decisivo papel da ação coletiva consciente do governo na solução de conflitos entre as instituições, o que sugere que o papel das mesmas (e dos mecanismos de ação coletiva) é assegurar certa "ordem" ao funcionamento do sistema. As decisões daí derivadas, ao se converterem em lei ou apoiadas no plano da política, tornam, dessa forma, as referidas instituições mais específicas, precisas e duradouras.

Com efeito, a diferença entre uma teoria que estabeleça as instituições como parte de uma planificação consciente e coordenada e uma teoria que as conceba como resultado de um processo evolutivo não coordenado não se traduz necessariamente em uma diferença sobre se as instituições vigentes são"eficientes" ou não. Para a tradição institucionalista neoclássica, os trabalhos de Demsetz sobre direitos de propriedade incluíam a pressuposição de que "a lei era eficiente e que as mudanças legais refletiam mudanças em regras socialmente ótimas" (Nelson; Sampat, 2001, p. 240). Da mesma forma, parte dos estudos sobre organização dos negócios supõe que as formas organizacionais são escolhidas racionalmente, sendo, portanto, ótimas.

Atualmente, observa-se nas várias escolas institucionalistas, principalmente dentro da própria NEI, um afastamento dessas posições. Douglass North, em seus primeiros estudos, supunha que as instituições evoluíam de forma a alcançar níveis mais elevados de eficiência (Davis; North, 1971 apud Nelson; Sampat, 2001, p. 25). Em trabalhos mais recentes, como o de 1990, advoga que sociedades possuidoras de instituições relativamente eficientes são relativamente mais afortunadas (North, 2005). Nesse sentido, a ideia de que não é necessário serem as instituições eficientes desencadeia uma nova vertente teórica segundo a qual as instituições vigentes são quem, em última instância, explica as diferenças de desempenho econômico entre os países, dentro dos quais as mesmas assumem distintos arranjos institucionais locais. É esse o caminho que começa a ser esboçado na análise de Matthews e que toma forma mais definida em Zysman (1983), conforme também o sugere Hodgson (1998). Os estudos mais recentes de Douglass North e Richard Nelson revelam essa convergência. Depreende-se daí que "construir" um ambiente institucional adequado e mutante não implica necessariamente torná-lo mais eficiente: só a construção e evolução do mesmo poderá, no futuro, fornecer essa resposta, com base na experiência histórica adquirida. 


\subsection{Algumas abordagens institucionalistas e o processo de crescimento}

As abordagens institucionalistas têm contemplado em certa medida alguma teorização sobre o tema do crescimento econômico. Seus avanços, bem como seus limites, ocuparão este item. Nosso ponto de partida é o reconhecimento de que houve, nas últimas décadas, um revigoramento de estudos centrados nas instituições, consolidando seu campo de pesquisa (Chang, 2003; Hodgson, 1993; Samuels, 1995; Nelson, 1995; Matthews, 1986). Em função destes avanços algumas constatações podem ser feitas. Portanto, há que se buscar interpretar quais ferramentas contribuem para a compreensão do referido fenômeno. O que parece fundamental de se extrair dessa discussão é que crescimento, como processo, exige a construção de um ambiente adequado, articulado macro e microeconomicamente, associado a uma noção de mudança institucional e vinculado à abordagem evolucionária. O que se buscará constatar dessa discussão é que esses autores institucionalistas convergem com o campo de pesquisa evolucionário, que avança, conforme referido no estudo de Nelson (2002), na construção de uma ponte entre a incorporação do conceito de instituição e a compreensão do processo de crescimento econômico. Nesse sentido, Nelson propõe o conceito de "tecnologia social" para interligar estas duas noções, como se discutiu em Conceição (2012) ou em O’Hara (2007).

\subsubsection{Matthews e as fontes do crescimento econômico}

Matthews (1986), embora reconheça certa convergência nas modernas abordagens institucionalistas, argumenta que há várias diferenças entre elas. A começar pelo próprio conceito de instituição que, segundo ele, gravita em torno de três eixos. O primeiro identifica instituições econômicas alternativas como resultado de sistema de "direitos de propriedade" (property rights) alternativos. A segunda definição associa instituição a convenções ou normas de comportamento econômico, servindo como suporte à execução e cumprimento das leis. Nesta abordagem não há uma vinculação tão direta à economia dos custos de transação. E uma terceira derivação centra-se nos tipos de contrato, que pode se refletir em diferentes formas de autoridade. Estas são as razões que levam a definição de "instituição" 
a assumir conotações múltiplas. Sob essa perspectiva conceitual, o fenômeno de crescimento econômico é entendido como manifestação de mudanças institucionais. Vale dizer, o vínculo entre crescimento e instituições é realizado pelo conceito de mudança, que pressupõe inovações.

Como a fonte do crescimento econômico é a mudança institucional, a ideia de ótimo paretiano pode estar presente, desde que mesclada com elementos evolucionários, como a noção de processo contínuo e múltiplos equilíbrios, o que a transforma radicalmente. Matthews conclui que o processo de mudança econômica, institucional e tecnológica é completamente diferenciado de um processo de melhoras sucessivas e adaptativas que levem a uma única situação de convergência ao ótimo paretiano. Isso porque na realidade há uma série de fatores que obstaculizam tal perspectiva, como o papel do Estado, interações não voluntárias, inércia e complexidade.

\subsubsection{Zysman: instituições e trajetórias históricas de crescimento}

A abordagem de John Zysman (1994) enfatiza que as trajetórias de crescimento são criadas historicamente, a partir do desenvolvimento de trajetórias nacionais institucionalmente inventadas ou enraizadas (Historically rooted trajectories of growth). Ou seja, as instituições importam porque determinam diferentes trajetórias de crescimento econômico nos diversos ambientes nacionais. Há várias formas de se organizar as economias de mercado, os mercados são diferentes e há vários tipos de capitalismo. Esta abordagem procura associar mais diretamente institucionalismo à teoria econômica, estabelecendo nexos entre escolhas individuais, tipos de contrato e estrutura dos problemas enfrentados pelas suas respectivas empresas e organizações, originando as "instituições nacionais enraizadas historicamente". Pode-se tratar tal concepção como uma espécie de "institucionalismo histórico", sem deixar de referir que levanta problemas e propõe soluções considerando aspectos relacionados ao microeconomic-based institutionalism. Nesse sentido, diferentes conformações históricas e institucionais desenham, nos diversos contextos regionais, os sistemas nacionais de inovação, que distinguem as trajetórias tecno- 
lógicas. Por isto, institucionalismo e evolucionismo são fenômenos impossíveis de serem compreendidos de maneira desvinculada.

O ponto de partida da Historically rooted trajectories of growth é a recorrente crítica à noção de crescimento nas novas teorias de crescimento endógeno. Para Zysman, tanto o argumento de Romer, quanto o das informações assimétricas de Stiglitz, estão assentados em pressupostos de equilíbrio. Ao contrário, o pensamento evolucionário inspira-se nas particulares e, portanto, múltiplas, trajetórias nacionais, que independem do equilíbrio de steady state. Por esta razão, o reconhecimento implícito de trajetórias de crescimento abre espaço para que as instituições façam a mediação entre estas trajetórias, permitindo que se delineiem formas diferenciadas de desenvolvimento econômico. Neste contexto, é importante mencionar que são as estratégias, quer em nível empresarial, quer governamental, que, ao exercerem influência decisiva sobre as inovações, formam um ambiente adequado para os novos produtos e processos. Estabelece-se daí um importante ponto da passagem micro para a macro, pois não é o governo quem define estratégias para as firmas implementarem, mas o contrário, pois analiticamente o salto se manifesta do particular para o geral. Em outros termos, a capacidade do governo em produzir resultados em mercados específicos não cria inevitavelmente vantagens de crescimento no mais longo prazo e, alternativamente, seu fracasso em gerar ou criar vantagens não produz inevitavelmente desvantagens.

Segundo o modelo proposto por Zysman, e convergindo com a agenda de pesquisa neo-schumpeteriana discutida na seção 4 , as trajetórias de crescimento - cujas instituições são fontes geradoras - se dão tanto pela existência de padrões de inovação, quanto pelo desenvolvimento tecnológico. Através de rotinas e políticas específicas estabelecem-se os termos do desenvolvimento econômico. A opção que determina quem é perdedor ou ganhador torna-se parte do problema de alocação de custos nas mudanças industriais, envolvendo, independente do modelo de desenvolvimento industrial adotado, três aspectos sempre presentes: capacidade técnica da ação do Estado na economia; estabelecimento de uma política de alocação de custos da mudança industrial; e processo político para permitir tais cumprimentos. 
Assim, as estruturas institucionais nacionais são resultantes do processo histórico de desenvolvimento industrial e da modernização política, o que está diretamente associado à argumentação evolucionária das "trajetórias tecnológicas". Não basta a geração de investimento para criar as bases para um processo de crescimento. Faz-se necessária a construção de um ambiente institucional adequado capaz de transformá-lo em crescimento, o que obviamente implica uma série de outros fatores.

Pelo exposto, depreende-se que o ideário institucionalista está mais próximo do campo analítico heterodoxo do que no mainstream neoclássico, visto que seus princípios teóricos originaram-se da oposição aos fundamentos de equilíbrio, otimalidade e racionalidade substantiva. Qualquer abordagem analítica que se pretenda institucionalista deve incluir path dependency, reconhecer o caráter irreversivelmente diferenciado do processo de desenvolvimento econômico e pressupor que o ambiente econômico envolve disputas, antagonismos, conflitos e incerteza.

\subsubsection{North e o papel da mudança institucional}

Para Douglass North (1990), o fundamental no campo do desenvolvimento econômico é buscar a formulação de uma ainda inexistente "teoria da dinâmica econômica". E esta reside fundamentalmente na compreensão e sistematização do processo de mudança. Em sendo assim, as trajetórias das mudanças institucionais são elementos essenciais na definição das diferentes formas de crescimento econômico, o que revela notável semelhança com o pensamento evolucionário.

Para North, a mudança econômica de longo prazo é uma "consequência cumulativa" de inúmeras decisões de curto prazo tomadas por políticos e empresários, que, direta ou indiretamente (via efeitos externos), determinam a performance econômica. Entretanto, o grau, através do qual os resultados são consistentes com as intenções, refletirá se os modelos dos empresários são efetivamente "verdadeiros". Isto porque os modelos refletem ideias, ideologias e crenças que são, na melhor das hipóteses, apenas parcialmente refinadas e melhoradas por feedback de informações sobre as consequências atuais 
das políticas tornadas legitimamente legais. Em outros termos, as consequências de políticas específicas não são apenas incertas, mas imprevisíveis.

Em seu livro de 2005, North reforça a argumentação da necessidade de se compreender o processo de mudança econômica como principal fonte de explicação dos fenômenos vinculados ao processo de crescimento. Ao tentar desvendar a lógica de tão complexo processo, que necessariamente deve contemplar analiticamente aspectos institucionais relevantes e de difícil sistematização, North, mais uma vez, confronta tal necessidade com a fragilidade do instrumental neoclássico, apesar de seus notáveis avanços na área quantitativa. $\mathrm{Na}$ estrutura do referido livro, salienta que o processo de mudança econômica (e institucional) deve, necessariamente, contemplar os seguintes aspectos: a incerteza em um mundo não ergódico; os sistemas de crenças, cultura e ciência cognitiva; a consciência e a intencionalidade humanas. Esses aspectos, em conjunto, definem o que ele designa de arcabouço de interações humanas que permitem a construção da estrutura institucional.

\subsubsection{A contribuição evolucionária de Nelson}

Nelson (2002) argumenta que os economistas que mais vêm contribuindo para o desenvolvimento da teoria de crescimento evolucionária, ao longo dos últimos vinte anos, têm se motivado nessa tarefa pela percepção de que a teoria neoclássica de crescimento econômico, embora assinalando que a mudança tecnológica exerce papel central no crescimento econômico, é totalmente inadequada ao caracterizar abstratamente tal processo. Mais especificamente, tal teoria é incapaz de caracterizar o processo de crescimento econômico desencadeado pela mudança tecnológica, como ele próprio o faz em conjunto com Winter (Nelson e Winter, 1982). Em particular, o modelo neoclássico desconsidera o fato de que os esforços para o avanço tecnológico são, em grande medida, "cegos" (Nelson, 2002, p. 17).

Tal proposição não implica negar o propósito, a inteligência e o corpo de entendimento das tentativas em se avançar na forma de incorporar o avanço tecnológico. É o caso de diferentes inventores e equipes 
de $P \& D$, que permitiram avanços em diferentes áreas, cujas conquistas são virtualmente impossíveis de serem previstas, no sentido de captar o avanço inerente a elas. A noção de que o avanço tecnológico se dá através de um processo evolucionário tem se desenvolvido de forma independente por estudiosos que atuam em uma variedade de disciplinas, como na sociologia (Constant, 1980; Bijker, 1995, apud Nelson, 2002, p. 18), nos historiadores da tecnologia (Rosenberg, 1976; Vincenti, 1990; Petrosli, 1992; Mokyr, 1990, apud Nelson, 2002, p. 18), bem como por economistas interessados em modelagem (Nelson e Winter, 1982; Metcalfe, 1998; Saviotti, 1996 apud Nelson, 2002, p. 18).

Entretanto, deve-se reconhecer que a contribuição dos modernos economistas evolucionários sobre mudança tecnológica, preocupados com o papel das instituições no desenvolvimento econômico, tem tido poucos interlocutores. Por essa razão, Nelson (2002, p. 18) considera que a contribuição de seu artigo é servir como uma espécie de ponte entre as duas referidas tradições intelectuais e sugerir um caminho em que ambas possam seguir conjuntamente. Tal conjugação, para as tradições evolucionárias e institucionalistas, não constitui novidade porque, mesmo antes que a moderna teoria neoclássica ganhasse a atual preponderância, a maior parte da análise econômica era, tanto evolucionária, quanto institucionalista.

Sob esse aspecto, a ascensão hegemônica da teoria econômica neoclássica reduziu notavelmente o escopo intelectual implícito nas referidas abordagens, tornando a análise econômica evolucionária e institucionalista um corpo de estranho à teoria econômica. A tendência de dissonância em relação a essa hegemonia, no sentido de consolidação de uma trajetória própria, começou a ganhar espaço nos Estados Unidos principalmente com a contribuição de Commons, que ajudou a definir a escola institucional Americana. Sua análise, entretanto, não era muito evolucionária. Nem Coase, que mais tarde deu substância à Nova Economia Institucional, assumiu tal caráter. Tanto a chamada Nova Economia Institucional quanto a "Nova Economia Evolucionária" têm diferentes fontes e enfoques: a primeira ocupase com o conjunto de fatores que moldam e definem as interações humanas (segundo Commons) tanto dentro das organizações, como entre elas; e a última ocupa-se fundamentalmente com o processo de avanço tecnológico. Entretanto, mais recentemente, o desenvolvimento em ambos os campos vem revelando ampla convergência, 
como os trabalhos de Hodgson (1988, 1993 apud Nelson, 2002, p. 18) e Langlois (1989 apud Nelson, 2002, p. 18) o revelam. Também os trabalhos de Douglass North, como se viu no item anterior, vem hoje apresentando grande proximidade teórica com a perspectiva evolucionária, notadamente ao enfatizar a maneira pela qual as instituições se formam e se modificam.

Por essas razões, os estudiosos desses dois campos têm aumentado seus interesses na compreensão dos determinantes da performance econômica, e como essa diferencia as nações ao longo do tempo. Os modernos teóricos evolucionários enfocam centralmente o que chamam de "tecnologias". E os economistas institucionalistas enfocam predominantemente as instituições. Para Nelson, o casamento entre ambos é bastante viável.

A partir das observações acima, e tomando como referência a contribuição de O'Hara (2007), o "revival" da recuperação da tradição heterodoxa nos últimos 40 anos parece estar dando lugar a tentativas de integração teórica, tanto em seus aspectos micro e macro, como também em tradições com origens distintas, como os evolucionários/ institucionalistas e os pós keynesianos/kaleckianos da tradição macroeconômica de crescimento liderado pela demanda. É dentro deste espírito que este trabalho se insere.

Com efeito, a conexão entre os desenvolvimentos teóricos evolucionários e institucionalistas e a endogeneização das elasticidades em modelos de crescimento com restrição de divisas nos permite proceder as conexões importantes entre as tradições aqui analisadas. Os modelos pós-keynesianos de crescimento com equilíbrio no BP mostram que o crescimento depende da relação entre as elasticidades-renda do comércio internacional, razão pela qual, para estimular o crescimento, é necessário mudar a razão das elasticidades de forma a relaxar a restrição externa que opera, sobretudo, nos países em desenvolvimento. Isto implica necessariamente levar em conta aspectos que a macroeconomia keynesiana/kaleckiana enfatiza, em consonância com os princípios evolucionários e institucionalistas.

Em geral, os referidos modelos assumem que as elasticidades refletem em grande parte a diversidade e o grau de sofisticação da estrutura produtiva de uma economia. Contudo, essas explicações são insuficientes, pois, mesmo com a diversificação e sofisticação da 
estrutura produtiva (processo de industrialização de grande parte dos países da periferia), permanecem os diferenciais de elasticidades entre os países, gerando a restrição externa ao crescimento. Neste contexto, abordagens recentes dentro dessa literatura assumem a hipótese de endogeneidade das elasticidades-renda (dependentes de variáveis macroeconômicas). Embora incipiente, o desenvolvimento dessa hipótese é um avanço, embora algumas de suas conexões que são propostas careçam de maior fundamentação teórica.

As abordagens evolucionária e institucionalista fornecem explicações importantes capazes de suprir essa lacuna teórica. A fundamentação teórica da hipótese de endogeneidade das elasticidades-renda passa pelo entendimento das contribuições dessas referidas abordagens. Especificamente em relação à teoria evolucionária, ressalta-se a necessidade de ampliar o entendimento sobre o papel do SI (e da possibilidade do catching $u p$ ), bem como dos fatores institucionais que o moldam.

\section{Considerações finais}

Os modelos de crescimento com restrição externa são um desdobramento natural da tradição do crescimento puxado pela demanda agregada, uma vez que, ao estenderem alguns dos principais insights do modelo benchmark de Thirlwall, permitem avançar no entendimento do papel da restrição externa e, sobretudo, do progresso tecnológico no processo de desenvolvimento. Argumentou-se que essas contribuições, juntamente com as advindas de outras correntes de pensamento, contribuem na explicação de quais são os determinantes das elasticidades-renda do comércio.

A abordagem pós-keynesiana tem avançado nesse sentido ao desenvolver uma série de contribuições tanto teóricas como empíricas que enfatizam o "problema das elasticidades". Não obstante, como demonstrado, existem desenvolvimentos das abordagens evolucionária e institucionalista que cobrem lacunas importantes dentro desse pensamento e que devem ser incluídas nas análises sobre o tema. Em outras palavras, existe um potencial de interação entre essas abordagens que permite a elaboração de um constructo teórico co- 
mum. Fundamentalmente, esta interação encontra na ideia de disrupção e path dependence seus elementos centrais. Simultaneamente a isto a referida agenda dá importância definitiva à compreensão das mudanças institucionais e tecnológicas, que desenham novas trajetórias de crescimento. Sem elas, a compreensão do processo de crescimento econômico fica esvaziada de conteúdo histórico e estrutural, dentro das várias economias nacionais.

A constatação analítica dos evolucionários e institucionalistas conecta-se implicitamente com a hipótese de endogeneidade das elasticidades-renda do comércio, embora em ambientes teóricos e conceituais diferentes. Ou seja, o que se procurou demonstrar ao longo do texto é que a endogeneidade das referidas elasticidades é dependente, entre outras variáveis, da estrutura produtiva, do desenvolvimento do Sistema Nacional de Inovações e do grau de desenvolvimento das instituições, o que conecta analítica e teoricamente as abordagens discutidas neste texto. É necessário salientar também que as variações na política econômica que afetam algumas dessas variáveis produzem alterações nas referidas elasticidades e que, portanto, as mesmas não devem ser consideradas exógenas nos modelos de crescimento. Em outras palavras, deve-se levar em consideração os efeitos que variações na política econômica têm, por exemplo, sobre o progresso tecnológico e a heterogeneidade produtiva. Isso implica que a restrição externa advinda da condição de equilíbrio do $\mathrm{BP}$ não é "exogenamente" dada pela razão entre as elasticidades-renda da demanda por exportações e importações, mas sim que a própria razão dessas elasticidades é endógena a variações na política econômica. Nesse contexto, existe a necessidade de se rever a estrutura desses modelos e algumas de suas conclusões, bem como as evidências empíricas a eles associadas.

Por fim, ressalta-se que a hipótese de endogeneidade das elasticidades é uma importante contribuição à tradição do crescimento puxado pela demanda agregada, pois permite conectar, entre outros, uma série de desenvolvimentos teóricos e empíricos alcançados pelos modelos de crescimento com restrição externa. Recentemente, alguns autores têm inserido essa hipótese em suas análises (Palley, 1996; McCombie e Roberts, 2002; Ferrari, Freitas e Barbosa-Filho, 2010; Missio e Jayme Jr., 2012), ainda que as explicações acerca da existência de diferença entre as elasticidades entre países industrializados (mesmo da periferia) sejam ignoradas e/ou incipientes. Como 
observado ao longo deste trabalho, essa explicação passa pela análise das características históricas, produtivas, tecnológicas, políticas, sociais e institucionais de cada país, bem como do seu engajamento internacional. Ou seja, ao mesmo tempo que ela permite conectar desenvolvimentos importantes dentro da referida tradição, ela requer uma análise mais ampla e profunda do próprio processo de crescimento. Logo, o entendimento do "problema das elasticidades" é mais complexo do que "a passagem de uma economia agrária para industrial", o que de alguma forma justifica a persistência de diferenças nas elasticidades do comércio, mesmo com a industrialização de grande parte da "periferia".

\section{Referências}

ABRAMOVITZ, M. Catching up, forging ahead, and falling behind. Journal of Economic History, Nova York, v. 66, n. 2, p. 385-406, 1986.

ALBUQUERQUE, E. M. National systems of innovation and Non-OECD countries: notes about a rudimentary and tentative "typology". Brazilian Journal of Political Economy, v.19, n. 4 (76), October December. 1999.

. Inadequacy of technology and innovation systems at the periphery. Cambridge Journal of Economics, 31, pp. 669-690, 2007.

ARAUJO, R. A.; LIMA, G. T. A structural economic dynamics approach to balanceof-paymentsconstrained growth. Cambridge Journal of Economics, v. 31, n. 5, p. 755-774, 2007.

BERNARDES, A. T.; ALBUQUERQUE, E. M. Cross-over, thresholds, and interactions between science and technology: lessons for less-developed countries. Research Policy, 32, pp. 865-885, 2003.

BOTTA, A. A structuralist north-south model on structural change, economic growth and catching-up. Structural change and Economic Dynamics, v. 20, pp. 61-73, 2009.

CIMOLI, M.; PORCILE, G.; ROVIRA, S. Structural change and the BOP-constraint: why did Latin America fail to converge? Cambridge Journal of Economics, 34(2) pp. 389-411, 2010

CIMOLI, M. and PORCILE, G. Global growth and International Cooperation: A structuralist perspective, Cambridge Journal of Economics, 35 (2), pp. 383-400, 2011.

CIMOLI, M. and PORCILE, G. Technology, structural change and BOP-constrained growth: A structuralist toolbox, Cambridge Journal of Economics, 38 (1), pp. 215-237, 2014.

CHANG, H-J. The market, the State, and institutions in economic development' in H-J. Chang (ed.), Rethinking Development Economics, Anthem Press, London, 2003.

CONCEIÇÃO, O. A. C. Há compatibilidade entre a "tecnologia social" de Nelson e a "causalidade vebleniana" de Hodgson? Revista de Economia Política, São Paulo. 2012, no. 1.

DIXON, R.; THIRWALL, A. A model of regional growth-rate differences on kaldorian lines". In: J. E. King, 1994, Economic growth in theory and practice, Edward Elgar, Aldershot, n 43, 1975.

DOSI, G. Sources, procedures and microeconomic effects of innovation. Journal of Economic Literature, v. 27, pp. 1126-1171, 1988. 
ELLIOT, D.; RHODD, R. Explaining growth rate differences in highly indebted countries: an extension to Thirlwall and Hussain. Applied Economics, 31, 1999.

FAGERBERG, J. Technology and international differences in growth rates. Journal of Economic Literature, v. 32, September, 1994.

FAJNZYLBER, R. F. La Industrializacion Trunca de América Latina, México, Nueva Imagem. 1983. $416 \mathrm{p}$.

Da Caixa preta ao Conjunto Vazio. In: BIELSCHOWSKY, R. (org) Cinquenta Anos de Pensamento na CEPAL. Record, 2000.

FERRARI, M. A. R; FREITAS, F. N. P; BARBOSA-FILHO, N. H. O papel da taxa de câmbio real nos modelos de restrição externa: uma proposta de releitura. Revista de Economia Política, vol. 33, $\mathrm{n}^{\mathrm{o}} 1$ (130), p. 60-81, janeiro-março/2013.

FREEMAN, C. Japan: a new national system of innovation? In: DOSI, G.; FREEMAN, C.; NELSON, R.; SILVERBERG, G.; SOETE, L. (Eds.). Technical change and economic theory. London: Pinter, pp. 330-348, 1988.

. The "National System of Innovation" in historical perspective. Cambridge Journal of Economics, v. 19, n. 1, 1995.

The national system of innovation in historical perspective. Revista Brasileira de Inovação, v.3, n. 1, 2004.

HODGSON, Geoffrey M. Institutional economics: surveying the 'old' and the 'new'. Metroeconomica, v. 44 , n. 1, p. 1-28, 1993.

. Varieties of capitalism and varieties of economic theory. Review of International Political Economy, v. 3, n. 3, p. 380-433, Autumn 1996.

. The approach of institutional economics. Journal of Economic Literature, v. 36, p. 166-192, Mar. 1998.

How economics forgot history: the problem of historical specificity in social science. London: Routledge, 2001.

JAYME JR., F. G; RESENDE, M. F. C. Crescimento econômico e restrição externa: teoria e a experiência brasileira. In: Renault Michel; Leonardo Mello. (Org.). Crescimento Econômico: Setor Externo e Inflação. 1ed.Brasília: IPEA, v. 1, p. 25-45, 2009.

KALDOR, N. A Model of Economic Growth. The Economic Journal, 67 (268), 591-624, 1957.

Causes of the slow rate of economic growth of the United Kingdom, Cambridge: Cambridge University Press, 1966.

KLEVORICK, A., LEVIN, R., NELSON, R.; WINTER, S. On the sources and significance of interindustry differences in technological opportunities, Research Policy, v. 24, n. 2, 185-205, 1995.

LEÓN-LEDESMA, M. Cumulative growth and the catching-up debate from a dis-equilibrium standpoint. In: MCCOMBIE, J.S.L. PUGNO, M. e SORO, B. (eds.) Productivity Growth and Economic Performance: Essays on Verdoorn's Law. New York: Palgrave, Macmillan, 2002;

LLERENA, P.; LORENTZ, A. Co-Evolution of Macro-Dynamics and Technological Change: an Alternative View on Growth. Revue d'économie industrielle. Vol. 105, pp. 47-70, 1er trimester, 2004a;

LLERENA, P. e LORENTZ, A. Alternative Theories on Economic Growth and the Co-evolution of Macro-Dynamics and Technological Change: A survey. LEM Working Paper Series, February, 2004b.

MATTHEWS, R. C. O. The economics of institutions and the sources of growth. The Economic Journal, v. 96, p. 903-918, Dec. 1986.

MISSIO, F.; JAYME JR, F. G. . Structural Heterogeneity and Endogeneity of Elasticities on the Balance of Payments Constrained Growth Model. In: Souziakis, Elias; Cerqueira, Pedro. (Org.). Models of Balance of Payments Constrained Growth. 1ed.London: Palgrave, v. 1, p. 239-267, 2012. 
. Restrição Externa, Câmbio e Crescimento em um Modelo com Progresso Técnico Endógeno. Economia e Sociedade, Campinas, v. 22, n. 2 (48), p. 367-407, ago. 2013.

MORENO-BRID, J. C. Capital flows, interest payments and the balance-of-payments constrained growth model: a theoretical and an empirical analysis. Metroeconomica, v. 54, n. 2, May 2003.

MOWERY, D. e ROSEMBERG, N. The influence of market demand upon innovation: A critical review of some recent empirical studies, Research Policy, 8: 102-153, 1979.

McCOMBIE, J.; THIRLWALL, A. Economic growth and the balance of payments constraint. New York: St. Martin's Press, 1994.

Economic growth and balance-of-payments constraint revisited. In: ARESTIS, P.; PALMA, G.; SAWYER, M. (Ed.). Markets, unemployment and economic policy. London: Routledge, 1997. v. 2.

MCCOMBIE, J.; ROBERTS, M. The role of the balance of payments in economic growth. In Setterfield, M. (org.). The Economics of Demand Led-Growth: challenging the supply-side vision of the long run. Edward Elgar: Aldershot, pp. 87-114, 2002.

NELSON, R. R. (Ed) National innovation systems: A comparative analysis, Oxford: Oxford U. Press, 1993.

. Recent evolutionary theorizing about economic change. Journal of Economic Literature, v. 33, p. 48-90, Mar. 1995.

.The agenda for growth theory: a different point of view. Cambridge Journal of Economics, v. 22, p. 497-520, 1998.

. Bringing institutions into evolutionary growth theory. Journal of Evolutionary Economics, Spring-Verlag, v. 12, p. 17-28, 2002.

. SAMPAT, Bhaven. Las instituciones como factor que regula el desempeño económico. Revista de Economía Institucional, n. 5, Segundo Semestre, 2001.

WINTER, Sidney G. Evolutionary theorizing in economics. Journal of Economic Perspectives. v. 16, n. 2, p. 23-46, Spring 2002.

NELSON, Richard R. Evolutionary theorizing about economic change. In: SMELSER, Neil J.; SWEDBERG, Richard (Ed.). The handbook of economic sociology. New York: Princeton University Press, Princeton \& Russel Sage Foundation, p. 108-136, 1994.

NORTH, Douglass C. Institutions, institutional change and economic performance. New York: Cambridge University Press, 1990.

. Economic performance through time. The American Economic Review. Vol. 84, nº 3 , jun. p. 359-368, 1994.

Understanding the process of economic change. Princeton and Oxford: Princeton University Press, 2005.

O'HARA, P. Principles of Institutional-Evolutionary Political Economy: Converging. Themes from the Schools of Heterodoxy. Journal of Economic Issues, 41, pp. 1-42, 2007.

PALLEY, T. I. Growth theory in a Keynesian mode: some Keynesian foundations for new endogenous growth theory. Journal of Post Keynesian Economics, vol 19, n. 1, pp. 113-135, 1996.

PEREZ, C.; SOETE, L. Catching up in tecnology: entry barriers and windows of opportunity, in: DOSI, G. et al. (Eds) Technical Change and Economic Theory (London: Macmillan), 1988.

PREBISCH, R. O desenvolvimento da economia da América Latina e alguns de seus problemas principais. In BIELSCHOWSKY, R. (org.) Cinquenta Anos de Pensamento na CEPAL. Record, p. 69-136, 2000a.

. Problemas teóricos e práticos do crescimento econômico. In BIELSCHOWSKY, R. (org.) Cinquenta Anos de Pensamento na CEPAL. Record, p. 179-276, 2000 b. 
PORCILE, G.; DUTRA, M.; MEIRELLES, A. J. Technology Gap, Real Wages and Learning in a BOP-Constrained Growth Model. Journal of Post Keynesian Economics, v. 29, p. 473-500, 2007.

RESENDE, M. F. C.; TORRES, D. R. National Innovation System, Trade Elasticities and Economic Growth, XXXVI Encontro Nacional de Economia (ANPEC), Salvador, 2008.

RODRIGUEZ, O. O estruturalismo latino-americano. Civilização Brasileira, Rio de Janeiro, 2009.

ROSENBERG, N. Inside the black box: technology and economics. Cambridge: Cambridge University, 1982.

SAMUELS, Warren J. The present state of institutional economics. Cambridge Journal of Economics, v. 19, p. $569-590,1995$.

SILVERBERG, G. and VERSPAGEN, B. Evolutionary theorizing on economic growth, in: Dopfer, K. (ed.). The Evolutionary foundations of economics. Cambridge University Press, 2006.

SUNKEL, O. Structuralism, Dependency and Institutionalism: An Exploration of Common Ground and Disparities. Journal of Economic Issues, v. 23, n. 2, pp. 519-533, 1989.

SCHUMPETER, J. A. The Theory of Economic Development, Cambridge, Mass.: Harvard University Press, 1934 (originally published in German in 1911).

Capitalism, Socialism and Democracy, London: Allen and Unwin, 1943 (originally published in the USA in 1942).

THIRLWALL, A. P. The Balance of Payments Constraint as an Explanation of International Growth Rate Differences. Banca Nazionale del Lavoro Quarterly Review, no 128, March, 1979.

THIRLWALL, A. P.; HUSSAIN, M. The balance of payments constraint, capital flows and growth rates differences between developing countries. Oxford Economic Papers, v. 34, 1982.

WILLIAMSON, Oliver E. Las instituciones económicas del capitalismo. México: Fondo de Cultura Económica, 1985.

Transaction cost economics and organization theory. Industrial and Corporate Change, v. 2, n. 2, p. 107-156, 1993.

Transaction cost economics. In: SMELSER, Neil J.; SWEDBERG, Richard (Ed.). The handbook of economic sociology. New York: Princeton University Press, Princeton \& Russel Sage Foundation, 1994. p. 77-107.

Hierarquies, markets and power in the economy: an economic perspective. Industrial and Corporate Change, v. 4, n. 1, p. 21-49, 1995.

VERSPAGEN; B. Evolutionary Macroeconomics: A synthesis between neo-Schumpeterian and post-Keynesian lines of thought. The Electronic Journal of Evolutionary Modeling and Economic Dynamics, 2002;

ZYSMAN, J. Governments, markets and growth: financial systems and the politics of industrial growth. Nova York, Cornel, 1983.

ZYSMAN, John. How institutions create historically rooted trajectories of growth. Industrial and Corporate Change, v. 3, n. 1, p. 243-283, 1994. 